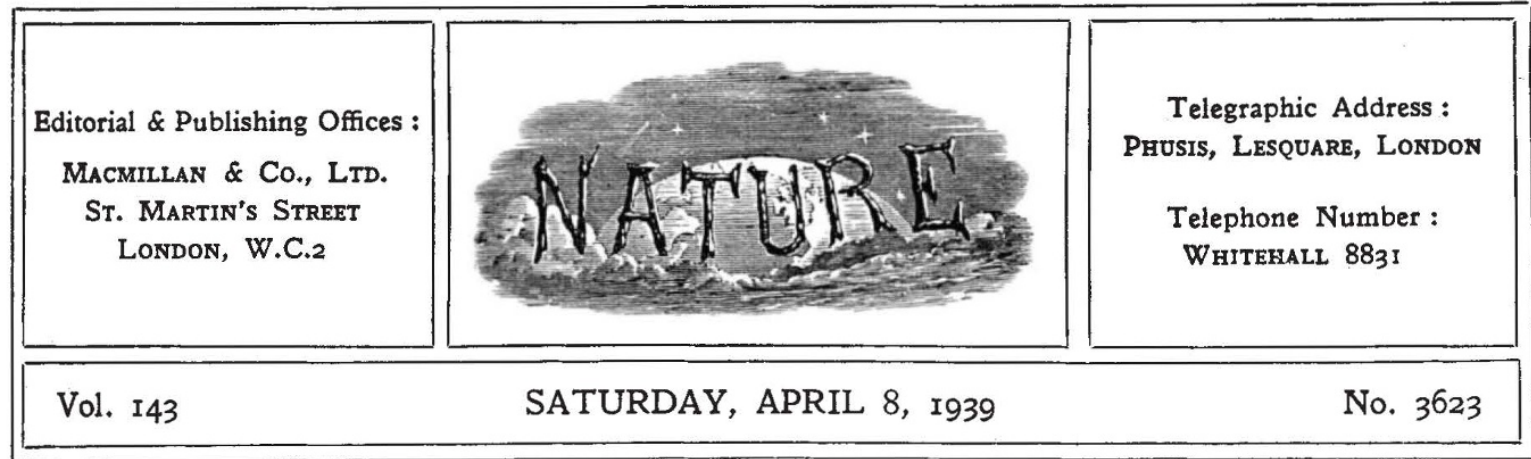

\title{
Scientific Research and the National Register
}

$\mathrm{O}^{\mathrm{F}}$ the importance of the part that will be played by men of science in the activities of any country that is, unhappily, engaged in modern warfare, there is no question. All are agreed on that point, and it is deeply to be deplored that the same agreement is not to be found concerning the contribution which they can make, and are ready to make, towards the solution of many of our peace-time problems, nor is the same desire shown to develop organizations which may serve to harness their abilities to that end. It is the tragedy of the times in which we live, that the forces of peace are unorganized, though collectively they are impressive enough in magnitude, and that the threat of war should be needed to orient and to organize man's activities to serve a common national need.

The best for which we can hope, in the present state of muddled thinking on the part of those to whom the nations of the world have confided their destinies, is that, should the shadow of war be lifted from the world, the organizations which the threat of war has called into being may be redirected and extended to serve more worthy ends. This has been done successfully in the past. The Ordnance Survey of Great Britain, which has developed almost beyond recognition since its inception at the end of the eighteenth century, and the pacific activities of which far transcend its wartime usefulness, took its origin from a war-measure ; and it needed the stress of the war of 1914-18 to call into being the Department of Scientific and Industrial Research. The plain truth is that man is an unimaginative creature, and Bastiat's argument concerning what is seen and what is not seen is pertinent to many more realms of thought than the economic one. Everyone's imagination is shocked by the thought of a great modern city pounded to a heap of smoking ashes; it is not so easy, in a bustling cheerful town, with cinemas filled to overflowing, and shops exhibiting merchandise gathered from the four corners of the earth, to realize that the country is faced with grave problems of malnutrition, problems the solution of which demands as close co-operation, as much teamwork, and as high and devoted enthusiasm as ever were brought to bear on a war-time problem. To-morrow is time enough for the problems which are not seen; the threat of war brings with it problems to be attacked to-day.

Among the needs of Great Britain at the present time is a register of names of those possessing professional, scientific, technical and higher administrative qualifications. Concerning the wartime value of such a register, there is no question; and it should be equally evident that it will have a high value for a nation which is awakening to the need for a successful attack on the problems of peace. It is the first step towards that coordination of our expert services which is so urgently needed; on the scientific side, it is the first instalment of that catalogue which will help us make a mental picture of the research activities of the country-to show us, in fact, what lack of co-ordination exists, what avoidable overlappings are evident, what gaps in our research problems need filling, and where border-line problems may most profitably be attacked.

The National Service Department of the Ministry of Labour is compiling such a register, and the register, in the event of war, will provide for the Government a list of persons willing to serve in their professional capacities in some appropriate way. The emphasis here is on the word 'appropriate'. The National Service Department is fully 
alive to the consequences of the errors of assignment made in the war of 1914-18, and is anxious to avoid a repetition of those errors, and to ensure that each man who offers his services is assigned to that task for which his knowledge, training and capacities best fit him. To that end the Royal Society has been asked to co-operate by compiling the section of the register dealing with persons "normally engaged in, or qualified to undertake, scientific research". These terms of reference should be carefully noted, for the register will defeat its own ends if it consists of an omnium gatherum of all persons who may be said to have had a scientific training, or who, without any special qualifications for research, are normally engaged in more or less routine work of a scientific character.

The officers of learned societies, and the heads of scientific departments in university and similar research institutions, have been asked by the Royal Society to furnish a list of those persons to whom an inquiry should be sent, and it is important here to note the relation between the Scientific Research Register and the Universities Register which was undertaken some months ago. Possibilities of overlap, confusion and of endless filling-in of forms are present in the minds of many inquirers, and it should be borne in mind that the Scientific Research Register undertaken for the Ministry of Labour by the Royal Society, as it is the latest, will probably be the last of its kind, and that it differs in three important respects from the Universities Register. In the first place, inclusion in the Scientific Register implies an obligation, "to serve [in wartime] in an appropriate way in their professional capacity and to accept such suitable work as is offered to them". It is perhaps desirable to emphasize this obligation, and to point out that the sub-committees set up to advise in the several subjects and to consider in advance the most suitable employment of individuals, consist of scientific men, who will approach their task with full knowledge. No obligation was, of course, implied in the Universities Register.

Again, the names of individuals included in the Scientific Research Register will not be included in the Universities Register. It is necessary to have a single register for all persons normally engaged in, or qualified to undertake, scientific research. It is obvious that a large proportion of such persons will not be in the universities, and it is therefore desirable to separate the two registers.

In the third place, the cards for the Universities
Register do not supply certain items of information which are regarded as important for the Scientific Research Register. In particular, no provision was made for that detailed classification of the individual's special qualifications, which is particularly important for the rapid and efficient use of the register.

The Ministry of Labour has set up a special Committee for Scientific Research of the Central Register Advisory Council, which will have the duty of dealing with the information given on the cards of this latest register. The names of the members of this Committee, which are given on another page (p. 592), and of the co opted members of the various sub-committees, afford sufficient guarantee that the problems of assignment will be handled efficiently and sympathetically, and that there is little danger, say, of the expert chemist's finding himself allotted to the elucidation of a problem in hydrodynamics, or being haled off to busy himself with minor work of an administrative kind.

The Scientific Research Register, it must be remembered, is part of a larger scheme, for the Ministry of Labour is engaged in compiling a Central Register of nine sections of which the Scientific Research Register is one, the remaining registers being devoted to General Engineering, Mining and Metallurgy, Industrial Chemistry, Architecture and Public Utilities, Universities and Teaching, Administration and Management, Accountancy, and Journalism, Languages, etc. It is inevitable that overlap will occur, and in such cases cross-references will be made.

The institution of such a register marks a great advance in the co-ordination of the national services of Great Britain and in the availability of the nation's experts. It is a signal advantage to have the information contained therein collected by one Department, and set out in a consistent fashion, so as to be readily available. The immediate stimulus for the production of this register is the spectre of war, on a scale and of an efficiency which are terrifying to contemplate. This, however, should not deter scientific workers from doing their part in making the register as comprehensive as possible; for, with due provision for keeping it up to date, it should be a lasting foundation on which to build up a scientific service covering all the activities of the nation in peace as well as in war, in preparation for the time when the gifts of science to mankind shall become the keystone of progressive civilization. 